\title{
TM5441, a plasminogen activator inhibitor-1 inhibitor, protects against high fat diet-induced non-alcoholic fatty liver disease
}

\author{
Seon Myeong Lee ${ }^{1, *}$, Debra Dorotea ${ }^{1, *}$, Inji Jung ${ }^{1}$, Tetsuo Nakabayashi², Toshio \\ Miyata $^{2}$ and Hunjoo $\mathrm{Ha}^{1}$ \\ ${ }^{1}$ Graduate School of Pharmaceutical Sciences, College of Pharmacy, Ewha Womans University, Seoul, Republic of Korea \\ ${ }^{2}$ United Centers for Advanced Research and Translational Medicine, Tohoku University Graduate School of Medicine, Miyagi, \\ Japan \\ *These authors contributed equally to this work
}

Correspondence to: Hunjoo Ha, email: hha@ewha.ac.kr

Keywords: plasminogen activator inhibitor 1, non-alcoholic fatty liver disease, high-fat diet, insulin resistance, organelle biogenesis

Received: April 11, 2017

Accepted: September 03, 2017

Published: September 21, 2017

Copyright: Lee et al. This is an open-access article distributed under the terms of the Creative Commons Attribution License 3.0 (CC BY 3.0), which permits unrestricted use, distribution, and reproduction in any medium, provided the original author and source are credited.

\section{ABSTRACT}

Recent evidences showed that elevation of plasminogen activator inhibitor 1 (PAI-1) was responsible in mediating obesity-induced non-alcoholic fatty liver disease (NAFLD) and metabolic disorders. Here, we investigated the effect of TM5441, an oral PAI-1 inhibitor that lacks of bleeding risk, on high-fat diet (HFD)-induced NAFLD. HFD-fed C57BL/6J mice was daily treated with $20 \mathrm{mg} / \mathrm{kg}$ TM5441. To examine the preventive effect, 10-week-treatment was started along with initiation of HFD; alternatively, 4-week-treatment was started in mice with glucose intolerance in the interventional strategy. In vivo study showed that early and delayed treatment decreased hepatic steatosis. Particularly, early treatment prevented the progression of hepatic inflammation and fibrosis in HFD mice. Interestingly, both strategies abrogated hepatic insulin resistance and mitochondrial dysfunction, presented by enhanced p-Akt and p-GSK3 $\beta$, reduced p-JNK signaling, along with p-AMPK and PGC-1a activation. Consistently, TM5441 treatment in the presence of either PAI-1 exposure or TNF-a stimulated-PAI-1 activity showed a restoration of mitochondrial biogenesis related genes expression on HepG 2 cells. Thus, improvement of insulin sensitivity and mitochondrial function was imperative to partially explain the therapeutic effects of TM5441, a novel agent targeting HFD-induced NAFLD.

\section{INTRODUCTION}

Non-alcoholic fatty liver disease (NAFLD) can range from simple steatosis, inflammatory steatohepatitis (NASH) with increasing severity of fibrosis, and ultimately cirrhosis [1]. The prevalence of NAFLD has risen steadily in parallel with the burgeoning number of obesity and diabetes patients. Therefore, NAFLD represents the most common cause of liver disease in developed countries $[2,3]$. However, detailed pathogenic mechanism of NAFLD progression is not yet fully understood which limits the development of therapeutic agents $[4,5]$.

Plasminogen activator inhibitor (PAI)-1 is a $50 \mathrm{kDa}$ single-chain glycoprotein and member of serine protease inhibitors. PAI-1 is widely known as an endogenous inhibitor of plasminogen activation by tissue-type and urokinase-type plasminogen activator (t-PA and u-PA, respectively) [6]. Plasma and tissue concentration of PAI1 are extremely low on basal condition but elevated under pathological conditions. Increased PAI-1 activity has been associated with higher risk of metabolic syndromes, cardiovascular events, and tissue fibrosis [7, 8].

Growing evidences coherently imply that PAI-1 mediates the development of hepatic steatosis in metabolic disorder condition. Clinically, a steady elevation of plasma and hepatic PAI-1 levels was correlated with the progression of NAFLD [9]. Animal studies, with either genetic- or diet-induced obesity, showed that PAI-1 
activation mediated obesity-induced insulin resistance [10-14]. In those studies, PAI-1 null mice improved glucose intolerance, insulin resistance, hyperlipidemia [11-13] and protected against hepatic steatosis [12, 14]. Additionally, PAI-1 knockout or knockdown in bile duct ligation (BDL) induced-mice might attenuate hepatic fibrosis [15-17]. Overall, those studies suggest that a complete PAI-1 deficiency alleviates a range of disorders found in NAFLD. However, no study has elucidated the therapeutic effect of pharmacological PAI-1 inhibition on liver injury.

Therefore, the present study investigated the efficacy of TM5441, a novel and orally active small molecule inhibitor of PAI-1, in ameliorating high fat diet (HFD)-induced NAFLD. TM5441 exceptionally lacks of bleeding risk and specifically inhibits PAI-1, no inhibitory effect was observed on other serine proteases, such as anti-thrombin III and $\alpha 2$-antiplasmin [18-20]. Numerous studies has demonstrated the protective effect of TM5441 and its analogue on various pathological conditions, such as hypertension [20], inflammation- and diabetic- induced kidney injury [21, 22], lung fibrosis [23], and cellular senescence $[24,25]$.

In response to those results, our previous study also showed the protective effect of TM5541 in HFDinduced obesity and adipocyte injury by maintaining mitochondrial function [26]. However, the role of PAI-1 in mitochondria remains controversial. PAI-1 overexpression in cancer-associated fibroblasts enhanced mitochondrial biogenesis in adjacent breast cancer cell which promotes metastasis [27]. Hence, investigating mechanism of PAI-1 inhibition on ameliorating HFD-induced NAFLD can be imperative to provide another insight of the role of PAI-1 in mitochondrial biogenesis.

The present study was specifically directed to investigate the effect of either early or delayed treatment of TM5441 in the HFD-induced NAFLD. Emphasizing on its capacity in remodeling insulin signaling and mitochondrial fitness, we examined the efficacy of TM5441 in decreasing hepatic steatosis, inflammation, and ultimately fibrosis, which are the hallmarks of NAFLD progression.

\section{RESULTS}

\section{Early TM5441 treatment prevented HFD- induced hepatic steatosis}

Body weight and metabolic parameters of experimental animal in the prevention regimen were as described in our previous publication [26]. We showed that compared to ND mice, 10-week-HFD mice had significant elevations of hepatic TG content and lipid accumulation in liver tissue which were remarkably reduced in response to TM5441 (Figure 1A, 1B). Lipogenesis-related genes were also evaluated; Acc1, Scd1, Cd36, and PPAR $\gamma$ were significantly decreased in TM5441-treated mice (Figure 1C). While, lipid catabolism was significantly increased in response to TM5441 treatment as shown by elevations of PPAR $\alpha$ mRNA expression (Figure 1C) and ATGL protein level (Figure 1D).

\section{Early TM5441 treatment prevented hepatic insulin resistance in HFD-fed mice}

To investigate whether HFD-induced hepatic insulin resistance might be prevented by TM5441, we measured proteins involved in insulin signaling, such as Akt, GSK$3 \beta$, and JNK. Akt and GSK-3 $\beta$ phosphorylation were significantly decreased in HFD mice compared to ND mice, which were reversed in response to TM5441 (Figure 2A, 2B). Then, the elevated level of $\mathrm{p}-\mathrm{JNK}$ in HFD mice was effectively reduced by TM5441 treatment (Figure 2C).

\section{Early TM5441 treatment prevented HFD- induced hepatic inflammation}

To determine anti-inflammatory effect of TM5441 in HFD mice, we evaluated the expression of proinflammatory markers in the liver. Positive F4/80 IHC staining, along with mRNA expression of F4/80 and MCP-1 were significantly increased in HFD mice and reduced by TM5441 treatment (Figure 3A-3D). In spite of less statistical significance, TNF- $\alpha$ and NLRP3 showed similar increment trend in HFD mice, followed by reduction upon TM5441 treatment (Figure 3E, 3F).

\section{Early TM5441 treatment protected against HFD- induced hepatic fibrosis}

We further investigated the preventive effect of TM5441 on extracellular matrix (ECM) accumulation and fibrosis, the hallmarks of NAFLD progression. First, we confirmed the ECM accumulation in the liver of HFD mice presented by positive collagen area in Masson's trichrome stained section. Remarkably, this accumulation was reduced by TM5441 treatment (Figure 4A, 4B). The anti-fibrotic effect was further supported by decreased mRNA levels of fibrogenic genes, such as PAI-1, TGF- $\beta 1$, fibronectin, and collagen IV in TM5441-treated HFD mice (Figure 4C-4G). Finally, gelatin zymography of liver lysate revealed that TM5441 significantly induced MMP-9 activation in HFD mice (Figure $4 \mathrm{H}$ ), partially explaining the anti-fibrotic mechanism of TM5441.

\section{Early TM5441 treatment improved AMPK and PGC-1 $\alpha$ activity in HFD-fed mice}

For a further insight about how TM5441 halts the deterioration induced by high fat feeding, we evaluated its efficacy in modulating AMPK, a regulator of energy metabolic homeostasis [28], as well as PGC- 
$1 \alpha$, a master regulator of mitochondrial biogenesis [29]. AMPK activation was reduced in HFD mice and reversed upon TM5441 treatment (Figure 5A). Regarding the AMPK upstream, CaMKK $\beta$ was decreased in HFD and elevated in response to TM5441 treatment. On the other hand, the activity of LKB1 was not affected in response to either HFD or TM5441 treatment (Figure 5B). Then, mRNA and protein levels of PGC-1 $\alpha$ were decreased in HFD mice and brought to normal levels by TM5441 treatment (Figure 5C, 5D). Nrf2, a transcription factor interacted with PGC-1 $\alpha$, was also normalized in the treatment group (Figure 5E). Other PGC-1 $\alpha$ target genes were also measured. COX4-i mRNA expressions in HFD-fed mice were increased in response to TM5441 (Figure 5F). In spite of constant level of mtDNA following HFD, its mRNA expression was significantly increased in response to TM5441 treatment compared to both ND and HFD (Figure 5G).

\section{Delayed TM5441 treatment ameliorated HFD- induced NAFLD and metabolic disorders}

Besides prevention effects, we tested whether TM5441 treatment showed therapeutic benefit in HFD-fed mice that had developed metabolic disorders, presented by glucose intolerance state (Supplementary Figure 1A, 1B). TM5441 treatment attenuated HFD-induced hepatic TG content and lipid accumulation on hematoxylin and eosin (H\&E)-stained liver section (Figure 6A, 6B). Decreased plasma FFA and TG were also observed in HFD mice treated with TM5441 (Supplementary Figure 2A, 2B). In contrast, high plasma level of PAI-1 in HFD mice was not adequately decreased after 4-week-TM5441 treatment (Supplementary Figure 2C).

Then, we verified that delayed TM5441 treatment improved insulin sensitivity in HFD mice. First, GTT and ITT results suggested that after 2-3 weeks of TM5441 treatment, glucose and insulin tolerance were significantly improved in HFD mice (Figure 6C, 6D). Additionally, fasting plasma insulin level and HOMA-IR index of HFD mice were significantly reduced by TM5441 treatment (Figure 6E, 6F). Persistently, immunoblot results indicated increased Akt and GSK-3 $\beta$ phosphorylation, suggesting improved insulin signaling in response to TM5541 (Figure 6G). Finally, the effect of TM5441 on hepatic mitochondrial biogenesis of HFD-fed mice were also elucidated. Decreased p-AMPK and PGC-1 $\alpha$ were observed in HFD mice which were reversed by TM5441 treatment (Figure $6 \mathrm{H}$ ).
A

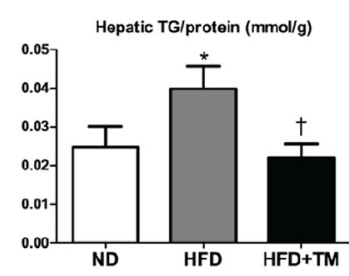

C

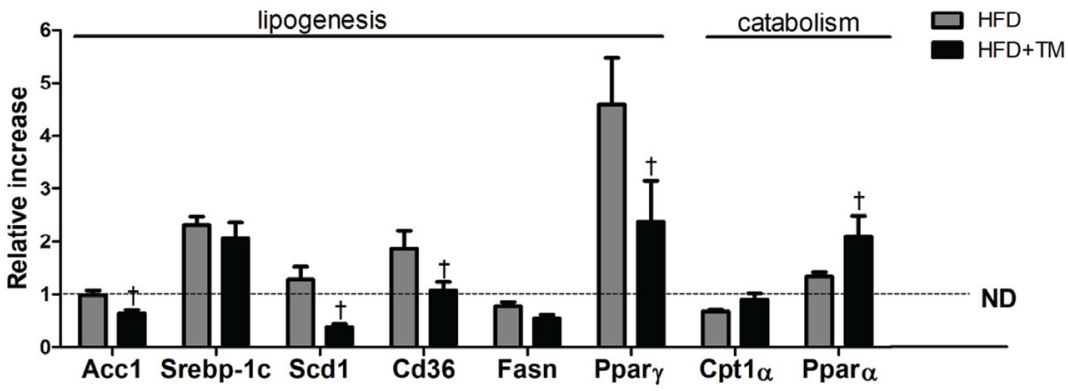

D

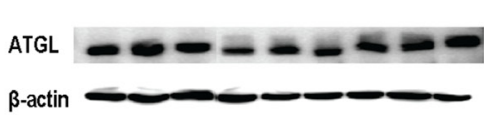

B

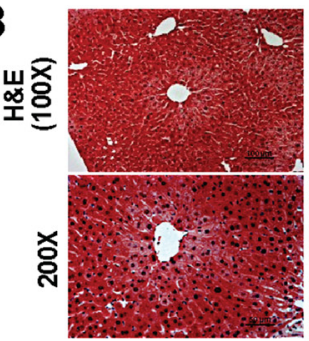

ND

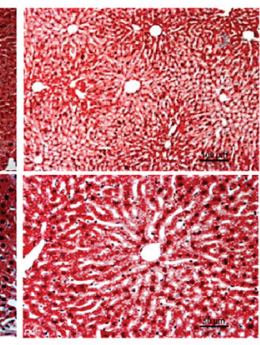

HFD

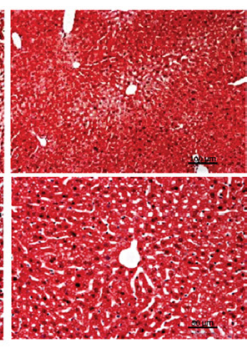

HFD+TM

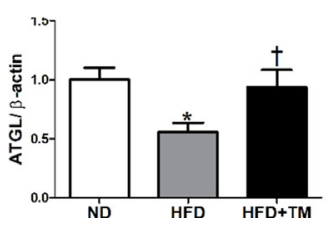

Figure 1: Early TM5441 treatment prevents HFD-induced hepatic steatosis. After 10-week-HFD, mice were sacrificed and hepatic tissues were analyzed. (A) Hepatic TG content/liver protein (mmol/g) was measured. (B) $5 \mu$ m liver section was stained with H\&E. The scale bar indicates $100 \mu \mathrm{m}$ and $50 \mu \mathrm{m}$ for $100 \times$ and $200 \times$ magnification, respectively. (C) mRNA expression levels of genes representing lipogenesis and lipolysis were quantified with RT-qPCR analysis. (D) Protein lysate of the liver was prepared for immunoblot analysis of ATGL. Data are shown as mean \pm SE of $7-8$ mice. ${ }^{*} p<0.05$ vs ND, ${ }^{\dagger} p<0.05$ vs HFD. 


\section{PAI-1 siRNA attenuated TNF- $\alpha$-induced mitochondrial dysfunction in HepG2 cells}

To examine the putative effect of PAI-1 in the hepatic mitochondrial function, the HepG2 cells was exposed to TNF- $\alpha$, a pivotal pro-inflammatory marker and one of the strongest PAI-1 activators [30]. TM5441 pre-treatment downregulated PAI-1 mRNA expression (Figure 7A) and upregulated mitochondrial biogenesis-related genes, such as PGC-1 $\alpha$, mtDNA, TFAM, NRF1, and NRF2 (Figure 7B). This result was further confirmed by silencing PAI-1 with siRNA in the presence or absence of TNF- $\alpha$ exposure (Figure 7C, 7D). In the basal condition, PAI-1 knockdown caused insignificant elevation of mitochondrial biogenesis-related genes. However, PAI-1 knockdown in the presence of TNF- $\alpha$ stimuli significantly increased PGC-1 $\alpha$, mtDNA, NRF1, and NRF2 mRNA level (Figure 7E).

\section{TM5441 inhibited PAI-1-induced mitochondrial dysfunction and lipid accumulation in HepG2 cells}

Since TNF- $\alpha$-induced mitochondrial dysfunction was reversed by PAI-1 knockdown, we investigated whether PAI-1 directly inhibited mitochondrial biogenesis. HepG2 cells treated with PAI-1 recombinant, especially $50 \mathrm{nM}$, showed upregulation of TGF- $\beta 1$ and fibronectin
A
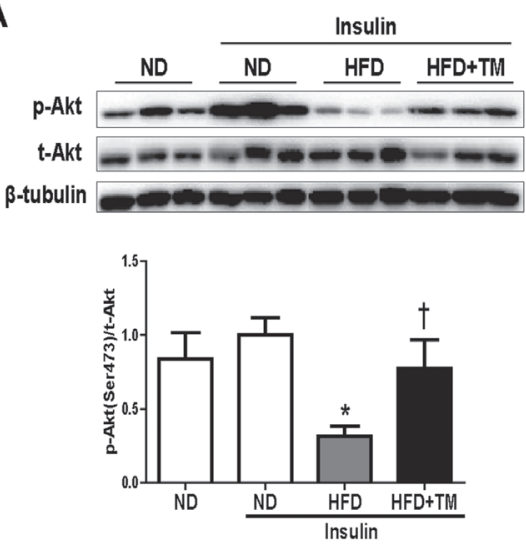

B
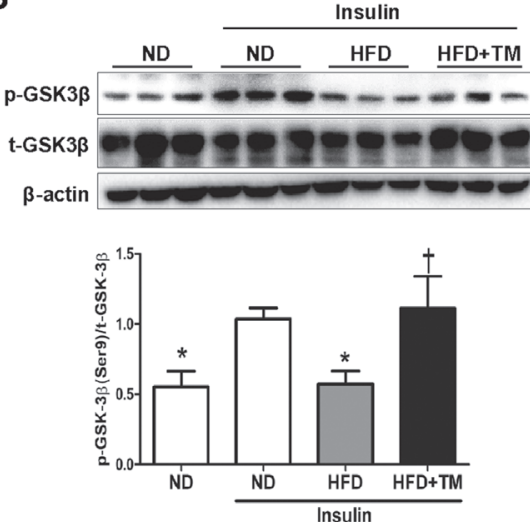

C
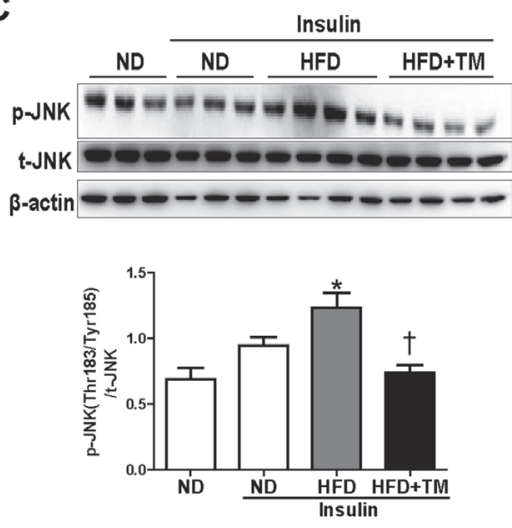

Figure 2: Early TM5441 treatment enhanced hepatic insulin signaling in HFD mice. During sacrifice, liver were taken before and after insulin injection. Then, protein lysate of the liver was prepared for immunoblot analysis of (A) Akt, (B) GSK-3 3 , and (C) JNK in both total and phosphorylated forms. Expression level of phosphorylated and total form quantified by densitometer and normalized with $\beta$-tubulin or $\beta$-actin as indicated. Data are shown as mean \pm SE of $7-8$ mice. ${ }^{*} p<0.05$ vs ND, ${ }^{\dagger} p<0.05$ vs HFD.

A

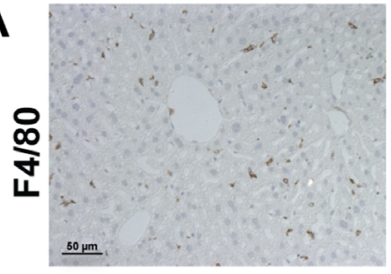

ND

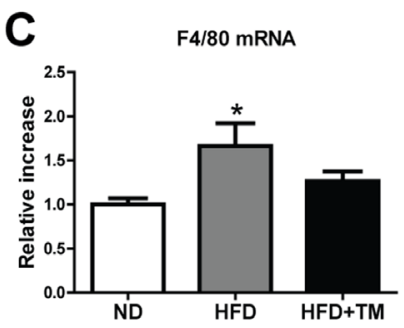

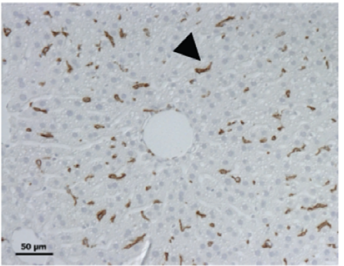

HFD

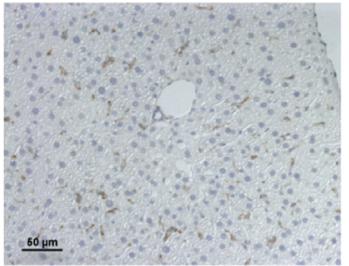

HFD+TM
B
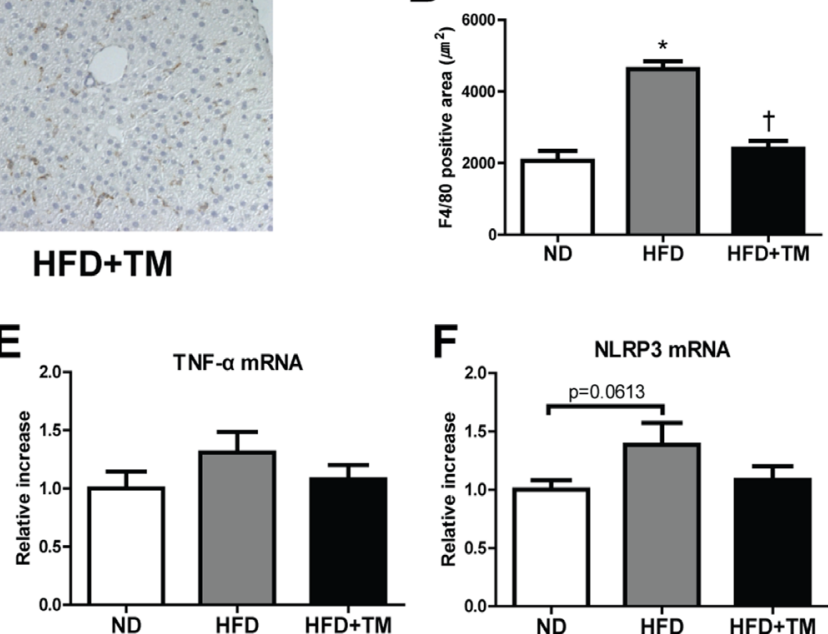

$\mathbf{F}$

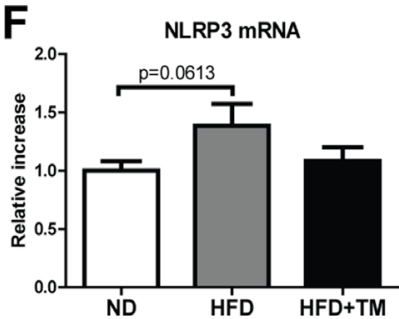

Figure 3: Early TM5441 treatment suppressed hepatic inflammation in HFD mice. (A, B) Anti-inflammatory effect of TM5441 was analyzed through quantifying positive F4/80 IHC staining area in the liver section. Magnification, $200 \times$; scale bar, $50 \mu \mathrm{m}$. Pro-inflammatory mRNA expressions in the liver, such as (C) F4/80, (D) MCP-1 (E) TNF- $\alpha$, (F) NLRP3, were measured by RT-qPCR. Data are shown as mean $\pm \mathrm{SE}$ of $7-8$ mice. ${ }^{*} p<0.05$ vs ND, ${ }^{\dagger} p<0.05$ vs HFD. 
mRNA level (Figure 8A), as well as downregulation of mitochondrial biogenesis genes, such as PGC- $1 \alpha$, mtDNA, and TFAM (Figure 8B). Accordingly, TM5441 pre-treatment under $50 \mathrm{nM}$ PAI-1 exposure, significantly reduced TGF- $\beta$ and fibronectin mRNA level (Figure 8C) as well as upregulated PGC-1 $\alpha$, mtDNA, and TFAM mRNA expressions, compared to identical concentration of PAI-1 in the absence of TM5441 (Figure 8D).

Since activation of PGC- $1 \alpha$ is associated with improvement of mitochondrial function, we confirmed whether TM5441 treatment can directly reduce excessive lipid accumulation and increase mitochondrial biogenesis in HepG2 cells. TM5441 pre-treatment significantly suppressed lipid droplet accumulation on HepG2 cells stimulated with PA, shown by less intensity of BODIPY staining (Figure 8E). Then, mitochondrial biogenesis was accentuated by increased of mitochondria labeled by Mitotracker ${ }^{\mathrm{TM}}$ staining upon TM5441 pre-treatment (Figure 8F).

\section{DISCUSSION}

Abundant results have demonstrated that complete PAI-1 deficiency protected against diet-induced insulin resistance and hepatic steatosis [11-14]. Interestingly, our present study is the first to establish the therapeutic effect of TM5441, a PAI-1 inhibitor, on HFD-induced NAFLD. Both early and delayed TM5441 treatment decreased hepatic triglyceride content and lipid accumulation. In particular, early treatment prevented the development of hepatic inflammation and fibrosis in HFD mice. Interestingly, deteriorated insulin signaling and mitochondrial biogenesis involved in the disease progression were remarkably reversed by both treatment strategies (Figure 9).

The development and progression of NAFLD represents a complex pathophysiology [31]. In the present study, we used HFD-fed mice to induce NAFLD. Although previous studies with HFD-fed rodents showed less consistency in progressing through liver

A

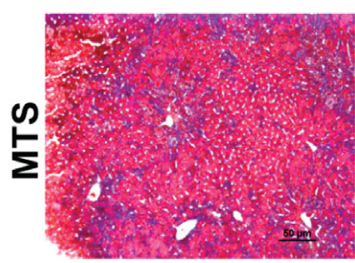

ND

C

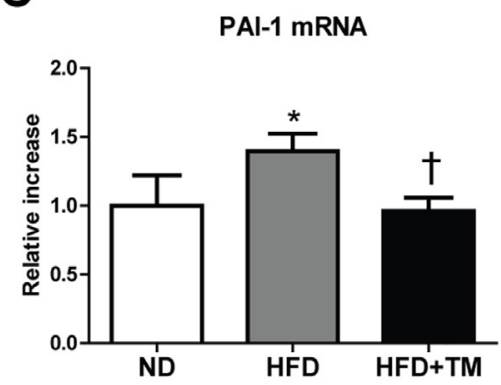

$\mathbf{F}$

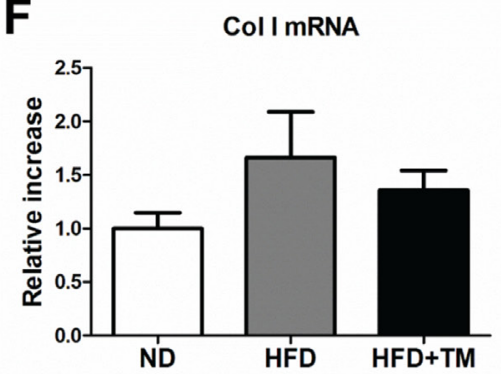

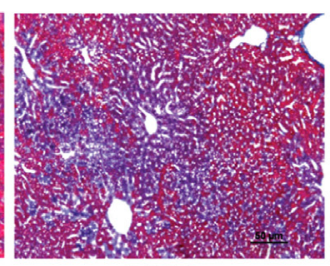

HFD

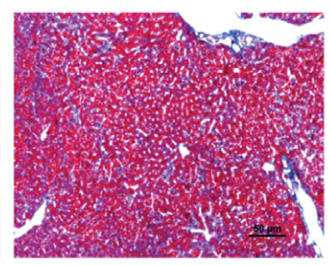

HFD+TM
B

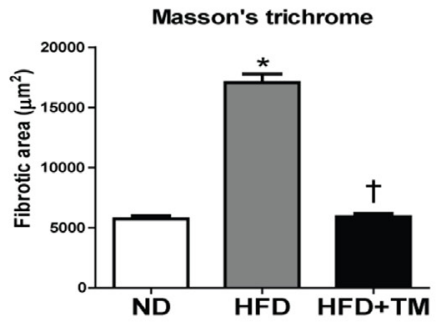

D TGF- $\beta$ MRNA $\quad$ E

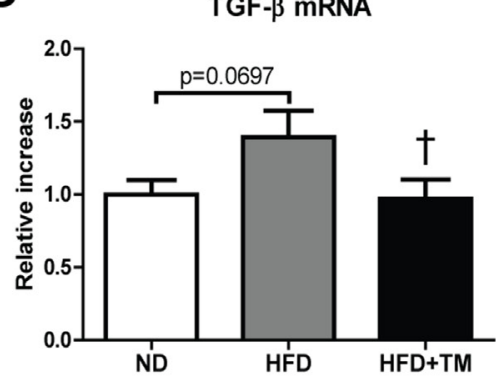

G

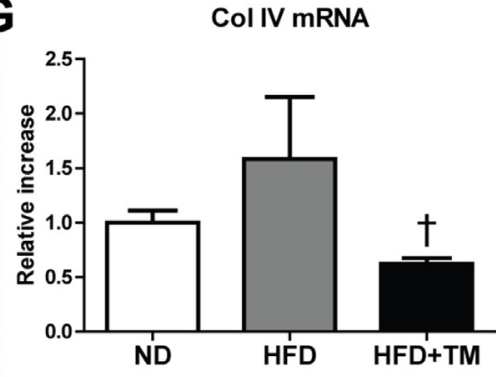

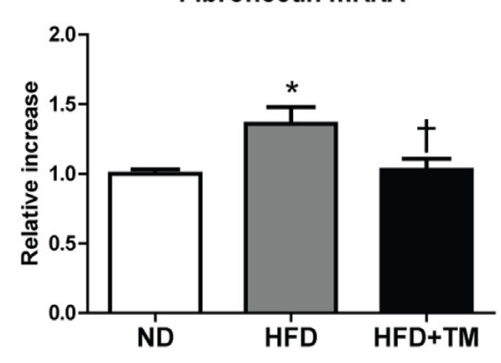

H
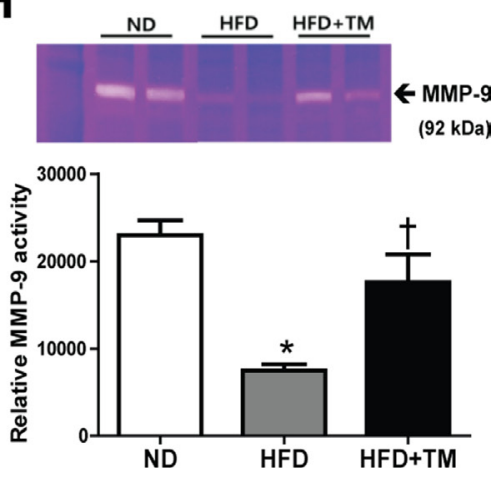

Figure 4: Early TM5441 treatment attenuates hepatic fibrosis in HFD mice. (A, B) Collagen accumulation in the liver was detected with Masson's trichrome staining. Magnification, 200x; scale bar, $50 \mu \mathrm{m}$. Liver mRNA expressions of (C) PAI-1, (D) TGF- $\beta 1$, (E) fibronectin, (F) collagen Ia1 (Col I), (G) collagen IVa1 (Col IV) were measured by RT-qPCR. (H) The activity of MMP-9, factor involved in ECM degradation, was measured with gelatin zymography. Data are shown as mean \pm SE of 7-8 mice. ${ }^{*} p<0.05$ vs ND, ${ }^{\dagger} p<0.05$ vs HFD. 
fibrosis, this model can replicate metabolic parameters alteration as found in human NAFLD, such as obesity, hyperinsulinemia, and insulin resistance [32].

In this study, 10-week-HFD presented hepatic steatosis, inflammation, and eventually fibrosis. As stated in previous publication, the metabolic parameters exhibited body-weight gain, insulin resistance, and higher serum PAI-1 [26]. The notion of insulin resistance was clearly presented by increased p-JNK along with reduced p-Akt and p-GSK3 $\beta$ in HFD mice. In the steatohepatitis, pro-inflammatory mediators activates JNK signaling, leading to insulin resistance [33]. Intricately, hepatic insulin resistance augments steatosis through increased de novo lipogenesis, decreased FFA oxidation, decreased very low-density-lipoprotein secretion, and increased FFA efflux due to increased adipose tissue's lipolysis [31].

Persistently, our study suggested an elevation of hepatic TG composition and lipid accumulation, as well as higher serum FFA and TG in HFD mice. Then, HFD obviously caused an excessive lipogenesis with a lower lipolysis rate. Early TM5441 treatment significantly downregulated lipogenesis-related genes (Acc1, Scd1, $\mathrm{Cd} 36$, and PPAR $\gamma$ ) and upregulated lipolysis-related genes $(\operatorname{PPAR} \alpha)$. Moreover, treated mice also exhibited an increase in ATGL, a major hepatic lipase regulating TG turnover [34, 35]. Hepatic steatosis was attenuated by TM5441 along with improvement of hepatic insulin sensitivity presented by decreased p-JNK along with increased $\mathrm{p}$-Akt and $\mathrm{p}$-GSK3 $\beta$. Moreover, delayed treatment might also bring the GTT, ITT, and fasting plasma insulin to the normal level as observed in ND mice.

The strong correlation between insulin sensitivity and intracellular TG content (i.e. liver and muscle tissues) has been well-established in human and animal studies of obesity-related insulin resistance and type 2 diabetes $[36,37]$. Lower TG content and lipid accumulation in liver in response to TM5441 is potentially a protective mechanism contributing to the improvement insulin sensitivity. This protection effect is supported by the result in HFD-fed PAI- $1^{-/}$mice. PAI-1 deficiency was related to lower hepatic TG and protection from obesity and insulin resistance. In PAI- $1^{-/-}$mice, increased skeletal muscle UCP-2 and UCP-3 may contribute to increased metabolic rates and energy expenditure, leading to protection against insulin resistance [12].

Moreover, inflammation and insulin resistance in adipose tissue during obesity can potentiate hepatic

\section{A}
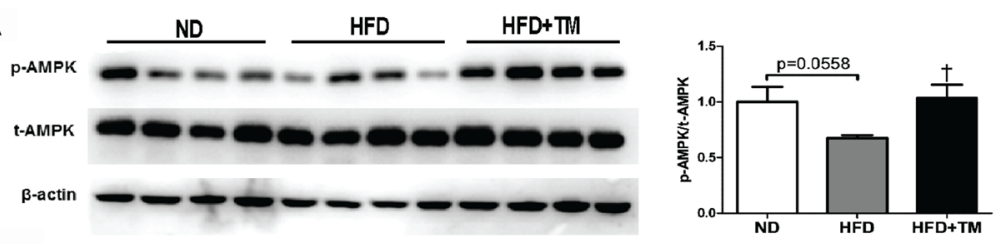

$\mathbf{B}$
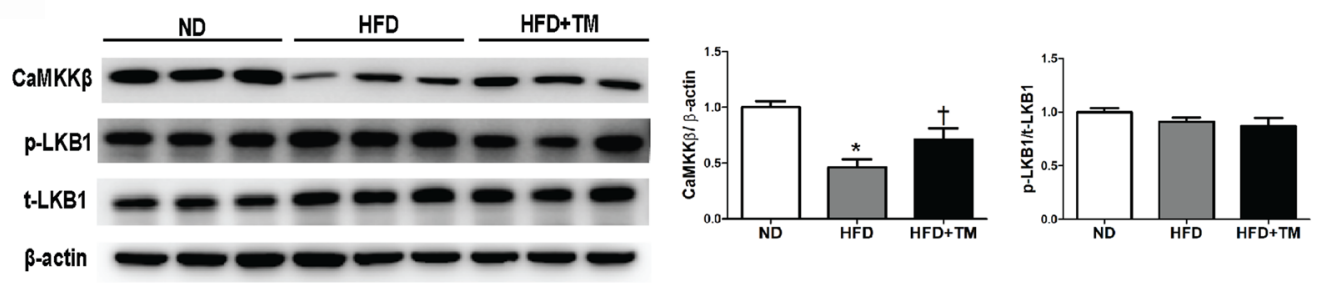

C
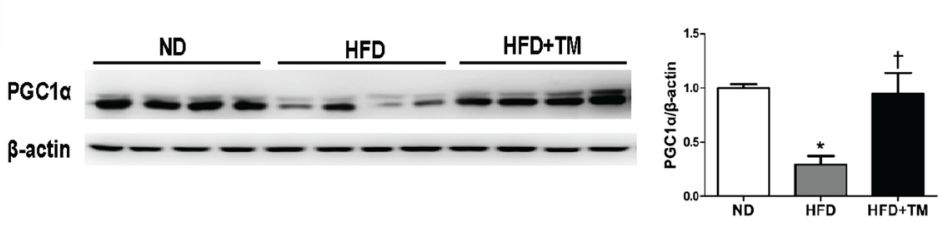

D

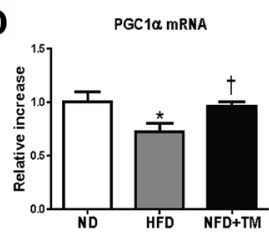

$\mathbf{E}$
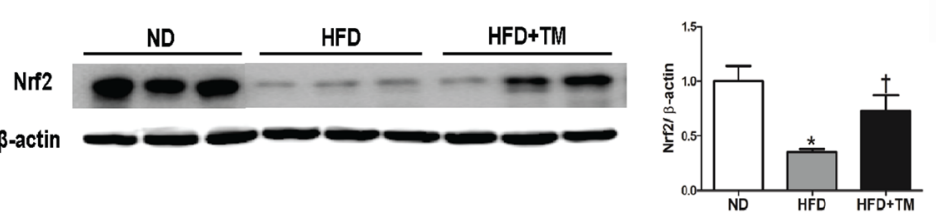

$\mathbf{F}$

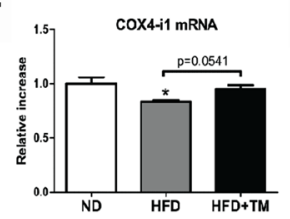

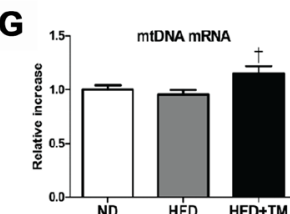

Figure 5: Early TM5441 treatment activates p-AMPK and PGC-1 $\alpha$ in HFD mice. Liver protein expressions of (A) total- and phospho- AMPK along with its upstream, including (B) CaMKK $\beta$, p-LKB1, and t-LKB1 were analyzed. Then, we measured the (C) protein and (D) mRNA expression of PGC-1 $\alpha$. (E) Protein expression of Nrf2, the transcription factor related to PGC-1 $\alpha$, and mRNA expression of genes related to mitochondrial biogenesis, such as (F) COX4-i1, and (G) mtDNA were all measured. Data are shown as mean \pm SE of 7-8 mice. ${ }^{*} p<0.05$ vs ND, ${ }^{\dagger} p<0.05$ vs HFD. 
inflammation, insulin resistance, and de novo lipogenesis that lead to steatosis [32]. In our previous study, early TM5441 treatment remarkably decreased body weight, lipid profile, and systemic insulin resistance. Particularly, in adipose tissue, it also attenuated inflammation, increased insulin sensitivity, as well as improved
A

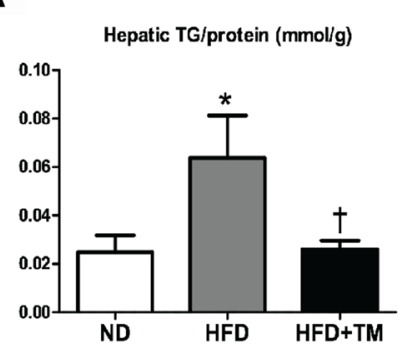

B

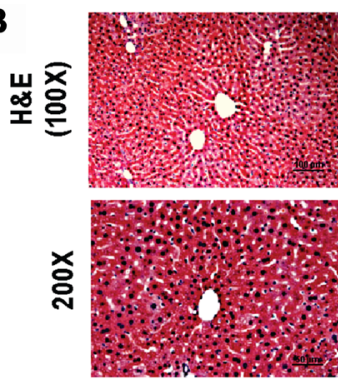

ND

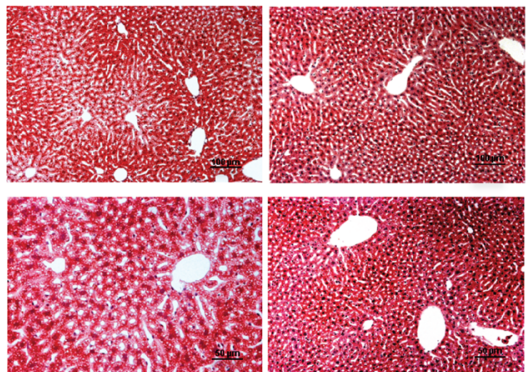

HFD

HFD+TM

\section{C}
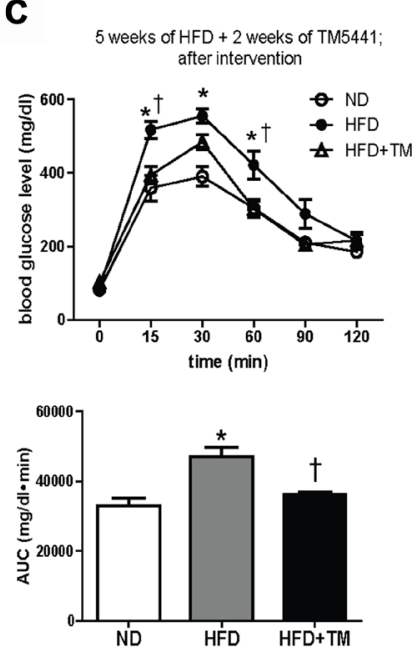

D
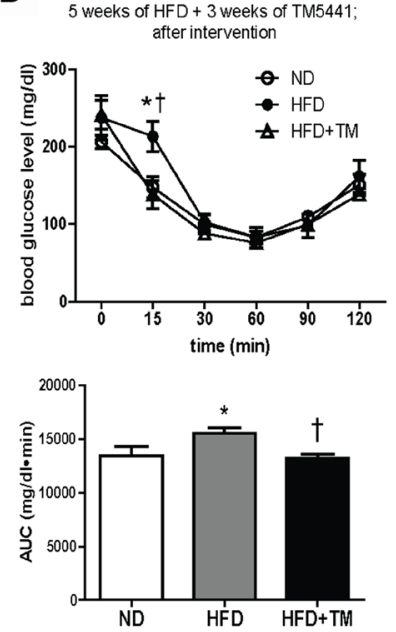

E

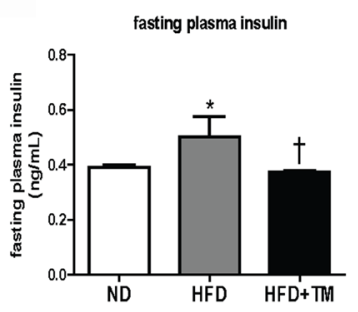

F

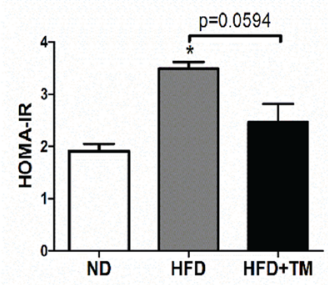

G
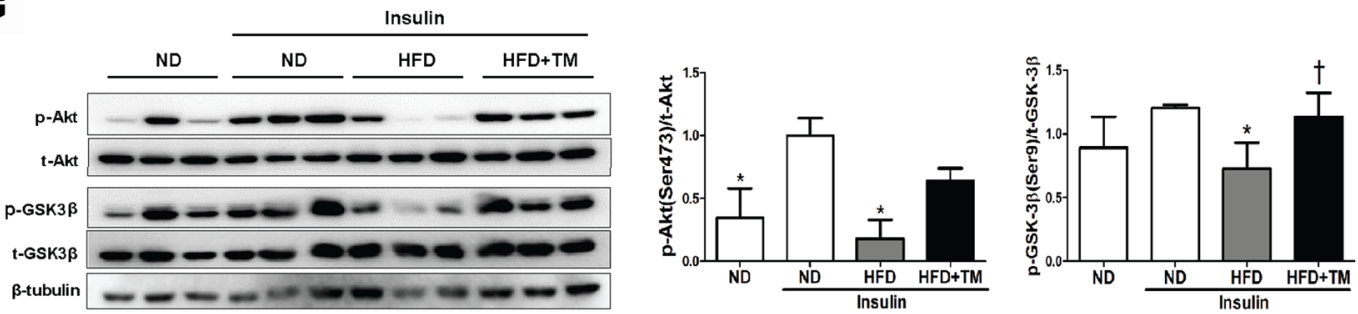

H
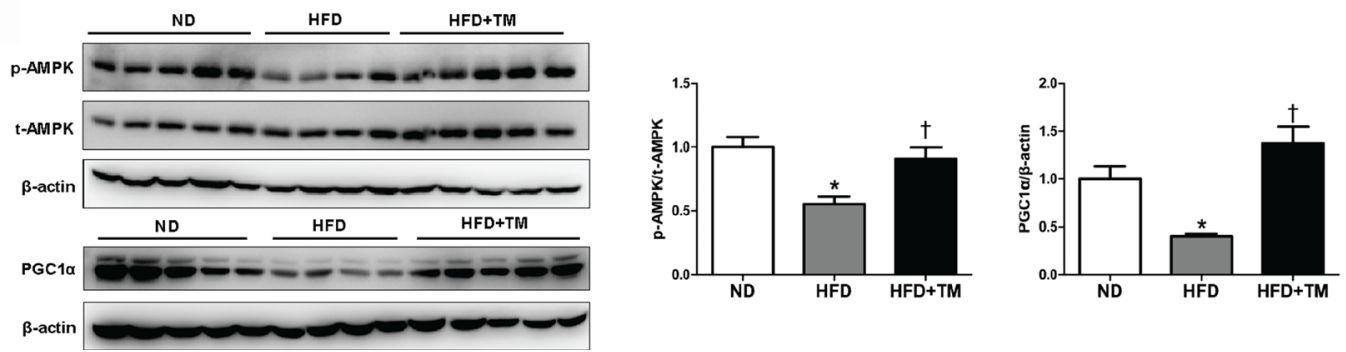

Figure 6: Delayed TM5441 treatment ameliorated HFD-induced NAFLD and metabolic disorder. 4-week-interventional treatment was initiated on 10-week-old HFD mice with glucose intolerance. (A) Hepatic TG content/liver protein (mmol/g) was measured. (B) H\&E staining depicted lipid accumulation in the liver. The black scale bar indicates $100 \mu \mathrm{m}$ and $50 \mu \mathrm{m}$ for $100 \times$ and $200 \times$ magnification, respectively. (C) GTT and (D) ITT measurement were performed after 2 weeks and 3 weeks of TM5441 treatment, respectively. AUC of blood glucose were then calculated and analyzed. (E) Fasting plasma insulin levels were measured and (F) HOMA-IR were subsequently calculated. (G) Immunoblot clarified insulin signaling activity presented through detection of Akt and GSK3 $\beta$ in the absence and presence of insulin stimulation. (H) Then, AMPK phosphorylation and PGC-1 $\alpha$ were analyzed to see the activation of mitochondrial biogenesis. Data are shown as mean \pm SE of $7-8$ mice. ${ }^{*} p<0.05$ vs ND, ${ }^{\dagger} p<0.05$ vs HFD. 
mitochondrial biogenesis [26]. Therefore, it is imperative to consider the action of TM5441 in preventing adipose tissue inflammation as a great contributor in ameliorating HFD-induced NAFLD.

Accordingly, we showed hepatic lipid accumulation in HFD-fed mice progressing to hepatic inflammation as shown by massive F4/80 infiltration, a major tissueresident macrophage in the liver [38], as well as elevated MCP-1 and NLRP3 mRNA level. Noticeably, aberrant inflammatory markers were abrogated in response to TM5441 treatment. This effect can be likely explained by a study in rat Thy-1 nephritis model treated with TM5275, an analog of TM5441. TM5275 hindered the interaction of PAI-1, identified as a chemotactic factor, with low-density lipoprotein receptor-related protein; thus, it may inhibited macrophage infiltration [21].

Albeit the notion that HFD-fed mice displayed less pronounced resemblance to pathological severity and fibrosis as seen in the liver of human NAFLD, our present study showed that 10 -week-HFD might progress to liver fibrosis. Our result was then indicated the antifibrotic effect of TM5441, as likewise described in lung fibrosis [23] and kidney fibrosis [22] models. Collagen accumulation in the liver of HFD mice, shown by Masson's trichrome staining, was significantly reduced by TM5441. Imperatively, our study indicated that MMP-9 activation by TM544 can partially explain its anti-fibrotic effect. MMPs are a family of endopeptidases that degrade ECM with a wide range of biological activities [39]. In agreement with our result, PAI-1 deficient mice showed MMP-9 elevation leading to TIMP-1 downregulation or tPA activation that may stimulate hepatocyte growth factor, a known anti-fibrogenic protein $[15,16]$. Alternatively, anti-fibrotic effect of TM5441 is likely through its direct inhibition on PAI-1 binding to hepatocyte surface receptors that might activate signaling pathway related to upregulation of TGF- $\beta$ and ECM genes [40].

Aforementioned results implied that our HFD mice exhibited the spectrum of hepatic steatosis, inflammation, and eventually fibrosis. In rodents and humans with
A
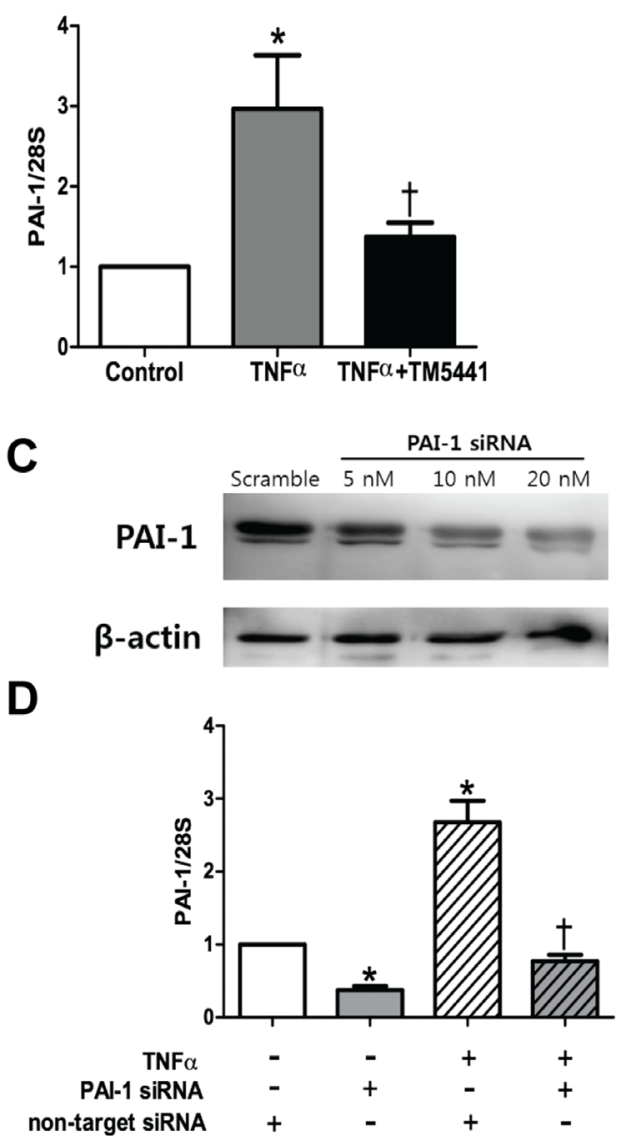

B

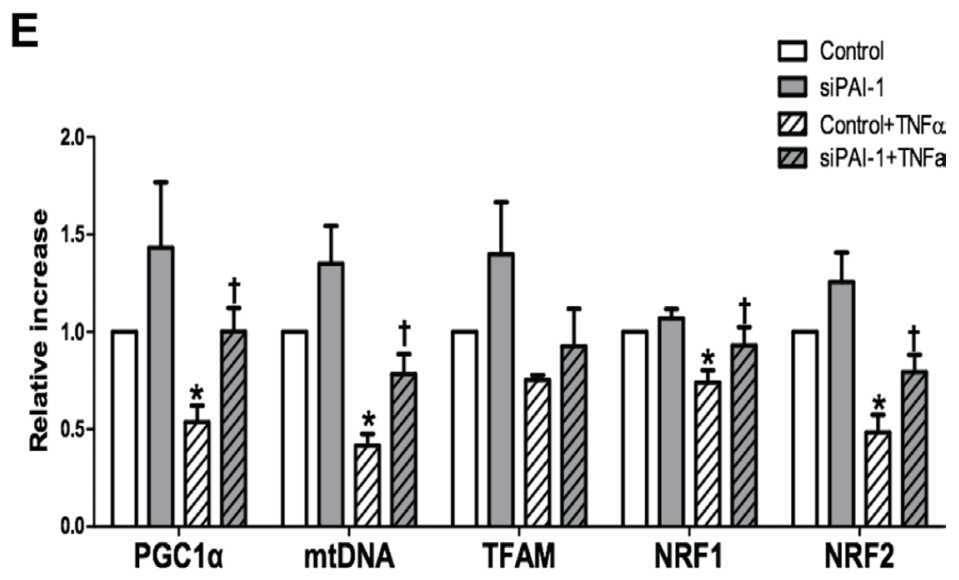

Figure 7: TM5441 pre-treatment and siPAI-1 improved TNF- $\alpha$-induced mitochondrial dysfunction in HepG2 cells. HepG2 cells were pretreated with $20 \mu \mathrm{M}$ TM5441 before the exposure of $50 \mathrm{ng} / \mathrm{ml}$ TNF- $\alpha$ for 24 hours. mRNA expressions of (A) PAI-1 and (B) mitochondria biogenesis-related genes, such as PGC-1 $\alpha$, mtDNA, TFAM, NRF1, and NRF2 were measured by RT-qPCR. Then, PAI-1 is downregulated with siRNA in which confirmed by immunoblot analysis. (C) $20 \mathrm{nM}$ siPAI-1 was transfected 24 hours before the exposure of $50 \mathrm{ng} / \mathrm{ml} \mathrm{TNF}-\alpha$ for 24 hour. The mRNA gene expression of (D) PAI-1 and (E) the mitochondrial function-related genes were measured by RT-qPCR. Data are presented as mean \pm SE of $4-5$ experiments. ${ }^{*} p<0.05$ vs. control, ${ }^{\dagger} p<0.05$ vs. control+TNF- $\alpha$. 
NAFLD, maladaptation of mitochondrial oxidative flux in the liver is a central feature of simple steatosis to NASH transition [41]. FFA overload on the mitochondria increases biosynthesis of toxic lipid intermediates that are potent inhibitors of insulin signaling in the liver and elicit multiple inflammatory pathways [41, 42]. This leads to higher rates of lipid peroxidation, formation of cytotoxic aldehydes, and production of pro-inflammatory cytokines, resulting in DNA damage and eventually cell death. Thus, a vicious cycle between insulin resistance and mitochondrial dysfunction is such an important target in halting the progression of NAFLD [41, 43].

In fact, both early and delayed treatment regimen showed that TM5441 elevated AMPK and PGC-
A

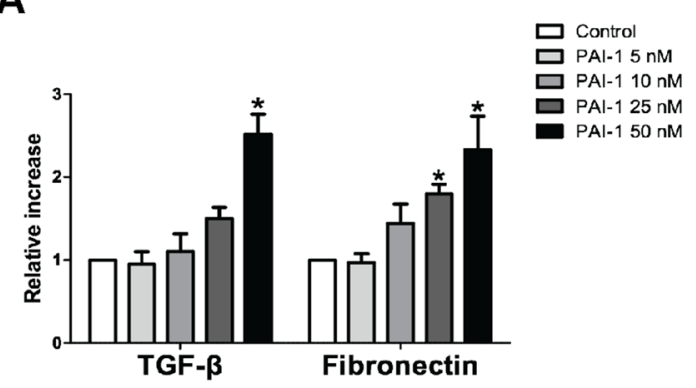

C

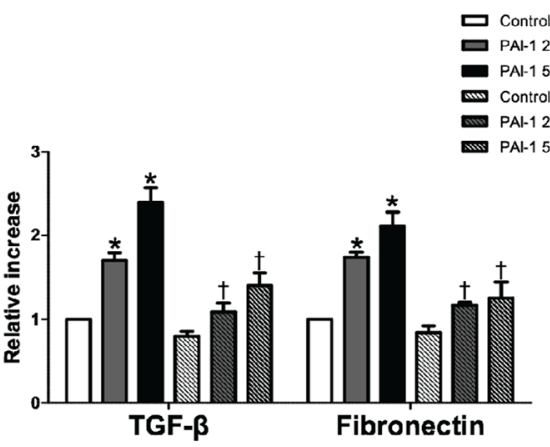

B

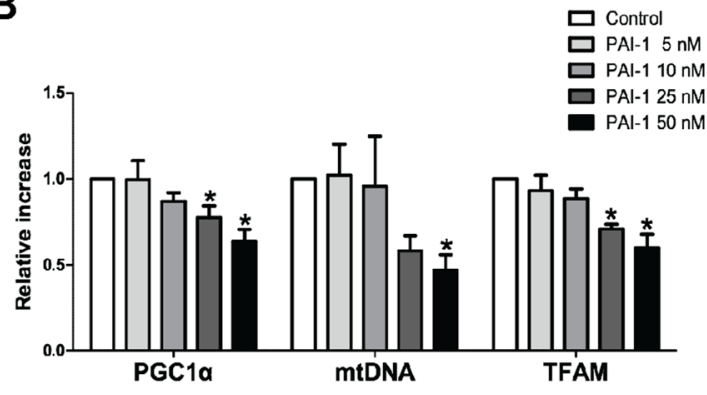

D

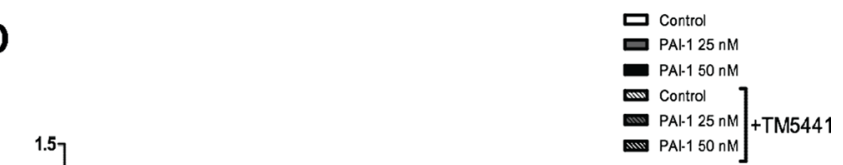

E
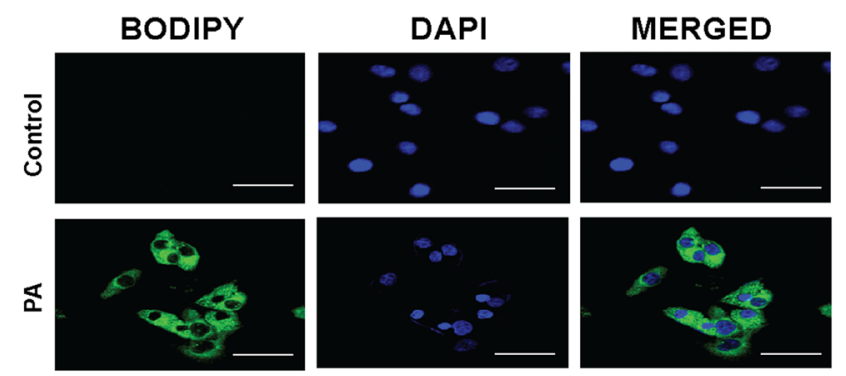

$\mathbf{F}$
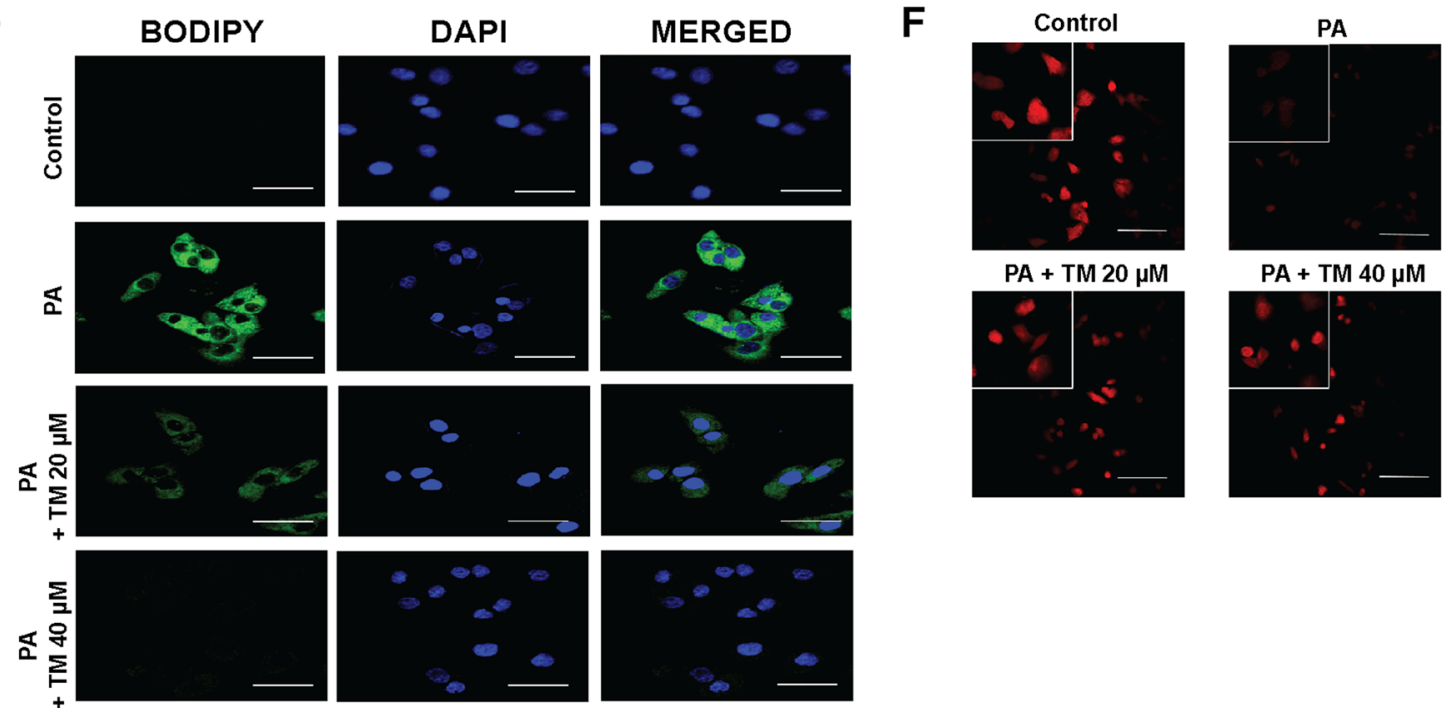

Figure 8: TM5441 inhibited downregulation of mitochondrial biogenesis-related genes and lipid accumulation in HepG2 cells. HepG2 cells were stimulated with PAI-1 recombinant for 12 hours, followed by measurement of (A) TGF- $\beta$, fibronectin, (B) PGC-1 $\alpha$, mtDNA, and TFAM mRNA expressions. Then, HepG2 cells were pre-treated with $20 \mu \mathrm{M}$ TM5441 prior to 12-hour-PAI-1 exposure ( 25 or $50 \mathrm{nM}$ ). The direct effect of TM5441 on mRNA expressions of (C) TGF- $\beta$ and fibronectin, (D) PGC-1 $\alpha$, mtDNA and TFAM were further analyzed. While, HepG2 cells was pre-treated with TM5441 (20 or $40 \mu \mathrm{M})$ prior to 24-hour-PA stimulation. (E) Neutral lipid accumulation was detected by BODIPY staining and (F) mitochondria was labeled with Mitotracker ${ }^{\mathrm{TM}}$ staining. Scale bar indicates $50 \mu \mathrm{m}$. Data are presented as mean \pm SE of 4 experiments. ${ }^{*} p<0.05$ vs. control, ${ }^{\dagger} p<0.05$ vs. response to the same concentration of PAI- 1 in the absence of TM5441. 
$1 \alpha$ activation, compared to HFD mice. Activation of AMPK, a master sensor to regulate metabolism, might ameliorate NAFLD via increasing hepatic insulin sensitivity, consequently suppressing hepatic de novo lipogenesis and increasing fatty acid oxidation, as well as promoting mitochondrial function in adipose tissue [44]. Interestingly, we further revealed that the upstream of AMPK activated by TM5441 treatment was CaMKK $\beta$, not LKB1.

Furthermore, activation of PGC-1 $\alpha$ suggested that the protection effect of TM5411 was contributed by improvement of mitochondrial biogenesis/function in NAFLD. Previous studies showed exacerbation of steatosis in mice with liver-specific deletion of PGC$1 \alpha$ [45]; in contrast, overexpression of hepatic PGC- $1 \alpha$ and subsequent increases in fatty acid oxidation through elevated mitochondrial content and/or function result in reduced TG storage [46]. In our study, activation of PGC$1 \alpha$ was observed along with activation of its respected transcription factor, i.e. PPAR $\alpha$ and Nrf2. Consequently, this may lead to activation of fatty acid $\beta$-oxidation enzymes, maintenance of mtDNA, expression of multiple components of the electron transport chain, as well as mitochondria biogenesis $[47,48]$.

However, the role of PAI-1 in regulating mitochondrial biogenesis remains controversial. The importance of PAI-1 as a therapeutic target in metabolic disorders was supported by a finding that hyperglycemiainduced mitochondrial superoxide production promoted PAI-1 expression [49]. Our previous report suggested that PAI-1 inhibition reduced adipose tissue inflammation and systemic insulin resistance through restoration of mitochondrial biogenesis [26]. Yet, another study demonstrated that cancer-associated fibroblasts overexpressing PAI-1 or PAI-2 displayed enhanced autophagy and further increases mitochondrial biogenesis in adjacent breast cancer cells [27]. Interestingly, our current results provide another evidence to support the

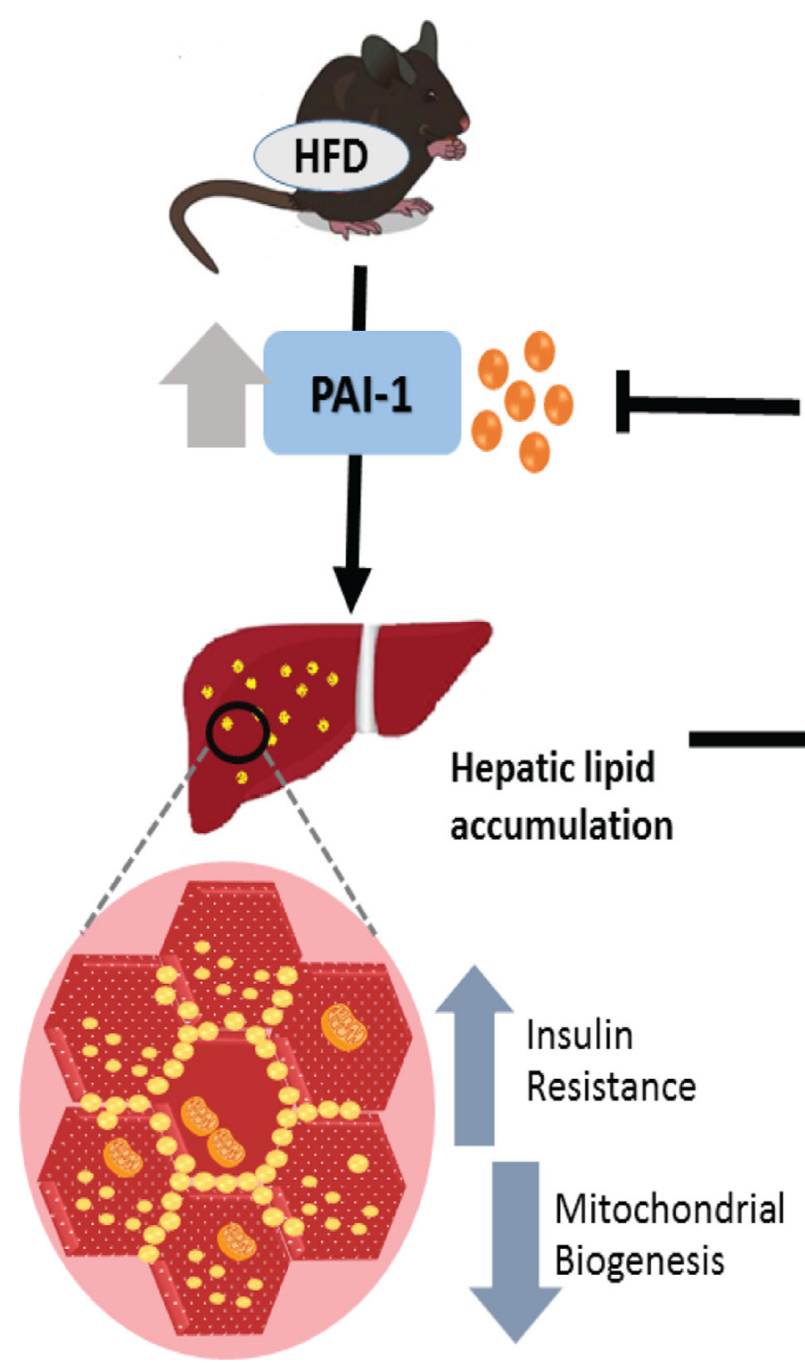

Figure 9: A schematic diagram showing the inhibition of PAI-1 by TM5441 ameliorates NAFLD partially through increasing mitochondrial biogenesis. 
notion that PAI-1 inhibition might reverse the deterioration of mitochondrial function.

The direct relation between PAI-1 and aberrant mitochondrial function was shown in our in vitro study with HepG2 cells. TNF- $\alpha$ stimulated-PAI-1 activity showed decreased mitochondrial biogenesis-related gene, including PGC-1 $\alpha$, mtDNA, NRF1, and NRF2 which were reversed by TM5441 treatment and silencing PAI-1 with siRNA. Persistently, in HepG2 cells stimulated with PAI-1 recombinant (25 \& $50 \mathrm{nM}$ ), TM5441 pre-treatment remarkably decreased markers of fibrosis (TGF- $\beta$ and fibronectin) and elevated mitochondrial biogenesis markers, including PGC-1 $\alpha$, mtDNA, TFAM. PGC- $1 \alpha$ activation is such an important process that related with mitochondria numbers and the oxidative phosphorylation capacity of each mitochondrion. PGC- $1 \alpha$ increases the expression of NRF-1 and mtTFA. The transcription of nuclear DNA-encoded respiratory chain polypeptides is increased by NRF-1, while mtTFA increases both the transcription and also the replication of mtDNA [29]. Then, in vitro study with PA stimulation revealed that TM5441 can directly decrease lipid accumulation and increase the intensity of mitochondria detected by BODIPY and Mitotracker ${ }^{\mathrm{TM}}$, respectively. This result supported our animal study in which a decreased hepatic lipid accumulation was found along with improved mitochondrial function upon TM5441 treatment.

Corroboratively, the present study showed that TM5441 activated PGC-1 $\alpha$, a mitochondrial biogenesis regulator, which might 1) increase fatty acid oxidation shown by increased lipolysis-related gene, decreased lipogenesis-related gene, and reduction of hepatic steatosis; 2) enhance insulin sensitivity, presented by insulin signaling activation, plasma insulin reduction, and normalization of GTT and ITT results.

In conclusion, this recent study demonstrated that both early and delayed TM5441 treatment ameliorated hepatic steatosis in HFD-induced NAFLD. In particular, early TM5441 treatment prevented the progression of hepatic inflammation and fibrosis. Both strategies also abrogate insulin resistance and promote increases in hepatic mitochondrial biogenesis. Thus, this finding suggested that TM5441, a PAI-1 inhibitor, can be a novel therapeutic agent in NAFLD.

\section{MATERIALS AND METHODS}

\section{Animal experiment}

Animal studies were approved by Institutional Animal Care and Use Committee (IACUC) at Ewha Womans University (No. 2011-01-079). 10-week-old $\mathrm{C} 57 \mathrm{BL} / 6 \mathrm{~J}$ male mice were housed in a room maintained at $22 \pm 2{ }^{\circ} \mathrm{C}$ with a $12 \mathrm{~h}$ dark/12 h light cycle, and fed either with normal diet (ND) or HFD (18.4\% proteinderived calories, $21.3 \%$ carbohydrate-derived calories and
$60 \%$ fat-derived calories, Harlan TD06414, Indianapolis, IN, USA). Control groups received $0.25 \%$ carboxymethyl cellulose by oral gavage; $20 \mathrm{mg} / \mathrm{kg}$ TM5441 was daily administered by oral gavage on HFD mice. TM5441 synthesized by Dr. Tetsuo Nakabayashi and Dr. Toshio Miyata were as described previously $[18,19]$.

To examine the prevention effect, 10-weektreatment of TM5441 was started along with the initiation of HFD on 10-week-old mice. Mice were sacrificed after $\mathrm{HF}$ feeding and treatment for 10 weeks. To examine therapeutic effect, 5-week-old mice were fed with HFD for 5 weeks, and 4-week-treatment of TM5441 was started on 10 -week-old mice with glucose intolerance. Following the end of 4-week-treatment course, mice were sacrificed.

\section{In vivo insulin stimulation}

For analyzing insulin signaling, mice were fasted overnight, anaesthetized and then injected via inferior vena cava with Humulin ${ }^{\circledR}(10 \mathrm{U} / \mathrm{kg}$, Eli Lilly, Indianapolis, IN, USA). Liver was removed 4 minutes after insulin injection.

\section{Glucose tolerance test (GTT) and insulin tolerance test (ITT)}

After $16 \mathrm{~h}$ fasting, GTT was performed by orally administering $2.0 \mathrm{~g}$ glucose $/ \mathrm{kg}$ body weight. Blood samples were taken from the tail vein to measure the glucose levels before and 15, 30, 60, 90 and $120 \mathrm{~min}$ after glucose administration. The ITT was conducted after $6 \mathrm{~h}$ fasting followed by an intra-peritoneal injection of $0.75 \mathrm{U} / \mathrm{kg}$ body weight Humulin (Eli Lilly). Blood glucose was measured by ACCU-Check glucose meter (Roche Diagnostics, Laval, QC, Canada).

\section{Measurements of metabolic parameters}

Blood was centrifuged at 3,000 rpm for 15 minutes at $4^{\circ} \mathrm{C}$, and plasma was collected. For plasma insulin measurements, commercial ELISA kits (R\&D Systems, Minneapolis, MN, USA) were used according to the manufacturer's instruction.

\section{Histochemical and immunohistochemistry (IHC) analysis}

Liver tissues were fixed in 4\% formalin, dehydrated, and embedded in paraffin. 5-micron-section was used for subsequent staining. H\&E and Masson's trichrome staining were performed to detect lipid accumulation and collagen accumulation, respectively. IHC staining was performed using immunoperoxidase procedures with a commercially available kit (Dako, Glostrup, Denmark). For detecting macrophage infiltration, anti F4/80 (1:200, Santa Cruz Biotechnology Inc., Santa Cruz, CA USA) was incubated overnight. Digital images were captured with 
Zeiss microscope equipped with Axio Cam HRC digital camera and Axio Cam software. For each liver section, 20 random fields were counted and mean value was used.

\section{Cell experiment}

HepG2 cells, human hepatoma cells (ATCC, Manassas, VA, USA), were maintained in Dulbecco's Modified Eagle's Medium (DMEM, Invitrogen, Carlsbad, CA, USA), supplemented with $10 \%$ fetal bovine serum (FBS, Invitrogen), $100 \mathrm{U} / \mathrm{mL}$ penicillin, $100 \mu \mathrm{g} / \mathrm{mL}$ streptomycin, and $44 \mathrm{mM} \mathrm{NaHCO} 3$ at $37^{\circ} \mathrm{C}$ in humidified $5 \% \mathrm{CO}_{2}$. Growth arrested and synchronized cells were exposed with $50 \mathrm{ng} / \mathrm{mL}$ tumor necrosis factor- $\alpha /$ TNF- $\alpha$ (Sigma-Aldrich, St. Louis, MO, USA) or 25 and $50 \mathrm{nM}$ mouse recombinant PAI-1 (EMD Millipore, Billerica, MA, USA) in the presence and absence of $20 \mu \mathrm{M}$ TM5441. TM5441 was added 4 hours prior to TNF- $\alpha$ or PAI- 1 stimulation. For PAI-1 knockdown in HepG2 cells, after reaching 70-80\% confluence, cells were seeded in 6-well plates with medium containing 20 nM PAI-1 siRNA (Santa Cruz, sc36179) or non-target siRNA (Bioneer, Daejeon, Republic of Korea) and LipofectaminTM RNAiMAX (Invitrogen, Carlsbad, CA, USA) according to the manufacturer's protocol and used for 24 hours transfection.

\section{Immunofluorescence analysis}

HepG2 cells were seeded and pre-treated with either 20 or $40 \mu \mathrm{M}$ of TM5441 for 4 hours prior to 400 $\mu \mathrm{M}$ palmitic acid (PA) stimulation for 24 hours. Neutral lipid was detected with BODIPYTM 493/503 (Invitrogen, Carlsbad, CA, USA) and nucleus was subsequently stained with DAPI (Invitrogen, Carlsbad, CA, USA). With the same experimental condition, mitochondria was stained using Mitotracker ${ }^{\mathrm{TM}}$ Red CMXRos (Invitrogen, Carlsbad, CA, USA). Following staining, the cells was fixed using $4 \%$ paraformaldehyde. The immunofluorescence stained cells were visualized using confocal microscopy (Carl Zeiss, Gottingen, Germany).

\section{Real-time quantitative reverse transcription PCR (qRT-PCR)}

The expression of mRNAs was assessed by realtime qRT-PCR using SYBR Green PCR Master Mix kit (Applied Biosystems, Foster City, CA, USA) with an ABI 7300 real-time qRT-PCR thermal cycler (Applied Biosystems). The mRNA expression levels of the tested genes were normalized to $18 \mathrm{~S}$ and $28 \mathrm{~S}$ rRNA levels. Primer sequences are listed in Supplementary Table 1.

\section{Western blot analysis}

Protein concentration in liver tissue homogenate and harvested cells was determined using the Bradford methods (Bio-Rad Laboratories, Hercules, CA, USA). Aliquots of tissue homogenates were mixed with sample buffer containing SDS and $\beta$-mercaptoethanol and heated at $95^{\circ} \mathrm{C}$ for $5 \mathrm{~min}$. The samples were then loaded into SDS-PAGE gel and separated by electrophoresis, followed by transfer process onto a PVDF membrane (GE Healthcare BioSciences Co., Piscataway, NJ, USA). The membrane was blocked for $1 \mathrm{~h}$ at room temperature with $5 \%$ skimmed milk in TBS-Tween 20 buffer, followed by an overnight incubation at $4^{\circ} \mathrm{C}$ in a $1: 1000$ dilution of the indicated antibodies. The commercial antibodies used were as mentioned in Supplementary Table 2.

\section{Zymography}

For matrix metalloproteinase (MMP) activity, zymography was performed using Novex 10\% zymogram protein gels (1.0 mm, 10 well) (Life Technologies, Carlsbad, CA, USA). Liver tissue homogenized in $1 \mathrm{~mL}$ lysis buffer (100 mmol/L Tris, 0.5\% Triton X-100 [pH 7.6]) without protease inhibitors was centrifuged $(15,000 \mathrm{~g}$, 15 minutes), supernatant was analyzed. Samples with equal concentrations of protein were mixed with TrisGlycine SDS Sample Buffer $(2 \times)$ (Novex). $100 \mu \mathrm{g}$ protein was electrophoresed on zymogram gel in a non-reducing Tris-glycine SDS running buffer. Gels were washed with renaturing buffer (Novex; $25^{\circ} \mathrm{C}, 30$ minutes), incubated in zymogram developing buffer (Novex; $37^{\circ} \mathrm{C}, 42$ hours), stained with $0.1 \%$ Coomassie Brilliant blue R-250/50\% methanol $/ 10 \%$ acetic acid ( 1 hour), and finally de-stained (5\% methanol $/ 7 \%$ acetic acid).

\section{Statistical analysis}

All results are expressed as mean \pm standard error (SE). ANOVA was used to assess the differences among multiple groups. $p$ value $<0.05$ was considered significance.

\section{Abbreviations}

ACC, acetyl-CoA carboxylase; ATGL, adipose trigyceride lipase; AMPK, AMP-activated protein kinase; BDL, bile duct ligation; $\mathrm{CaMKK} \beta, \mathrm{Ca}^{2+} /$ calmodulindependent protein kinase kinase $\beta$; Cptl $\alpha$, carnitine palmitoyl CoA transferase-1 $\alpha$; ECM, extracellular matrix; FFA, free fatty acid; GSK-3 $\beta$, glycogen synthase kinase-3 $\beta$; GTT, glucose tolerance test; H\&E, hematoxylin and eosin; HFD, high-fat diet; HOMA-IR, homeostatic model assessment of insulin resistance; IHC, immunohistochemistry; ITT, insulin tolerance test; JNK, c-Jun N-terminal kinase; LKB1, liver kinase B1; MCP-1, monocyte chemoattractant protein-1; MMP, matrix metalloproteinase; mtDNA, mitochondrial DNA; NAFLD, nonalcoholic fatty liver disease; NASH, nonalcoholic steatohepatitis; ND, normal diet; NLRP3, NOD-like receptor family, pyrin domain containing 3; NRF, 
nuclear respiratory factor; PAI-1, plasminogen activator inhibitor-1; PGC1 $\alpha$, peroxisome proliferator-activated receptor $\gamma$ coactivator $1 \alpha$; PPAR, peroxisome proliferatedactivated receptor; Scd1, Stearoyl-CoA desaturase-1; SE, standard error; SREBP-1c, sterol regulatory element binding protein 1c; TFAM, Mitochondrial transcription factor A; TG, triglyceride; TGF- $\beta 1$, transforming growth factor $\beta 1$; TNF- $\alpha$, tumor necrosis factor- $\alpha$; t-PA, tissue-type plasminogen activator; u-PA, urokinase-type plasminogen activator.

\section{Author contributions}

S.M.L and I.J designed and performed the experiments, S.M.L and D.D analyzed the data and drafted the manuscript, T.N and T.M synthesized and supplied TM5441, H.H provided the concept and approved the final version of the manuscript.

\section{ACKNOWLEDGMENTS}

The authors acknowledge the excellent technical assistant of Jung Hwa Lee.

\section{CONFLICTS OF INTEREST}

The authors have no conflicts of interest.

\section{FINANCIAL SUPPORT}

This work was financially supported by NLRL through the National Research Foundation (NRF) of Korea (No. 2016R1A2B4006575).

\section{REFERENCES}

1. Dowman JK, Tomlinson JW, Newsome PN. Systematic review: the diagnosis and staging of non-alcoholic fatty liver disease and non-alcoholic steatohepatitis. Aliment Pharmacol Ther. 2011; 33:525-540.

2. Ng M, Fleming $\mathrm{T}$, Robinson $\mathrm{M}$, Thomson B, Graetz N, Margono C, Mullany EC, Biryukov S, Abbafati C, Abera SF, Abraham JP, Abu-Rmeileh NM, Achoki T, et al. Global, regional, and national prevalence of overweight and obesity in children and adults during 1980-2013: a systematic analysis for the Global Burden of Disease Study 2013. Lancet. 2014; 384:766-781.

3. Yang KC, Hung HF, Lu CW, Chang HH, Lee LT, Huang KC. Association of Non-alcoholic Fatty Liver Disease with Metabolic Syndrome Independently of Central Obesity and Insulin Resistance. Sci Rep. 2016; 6:27034.

4. Barb D, Portillo-Sanchez P, Cusi K. Pharmacological management of nonalcoholic fatty liver disease. Metabolism. 2016; 65:1183-1195.
5. Abdelmalek MF. NAFLD: The clinical and economic burden of NAFLD: time to turn the tide. Nat Rev Gastroenterol Hepatol. 2016; 13:685-686.

6. Ghosh AK, Vaughan DE. PAI-1 in tissue fibrosis. J Cell Physiol. 2012; 227:493-507.

7. Ha H, Oh EY, Lee HB. The role of plasminogen activator inhibitor 1 in renal and cardiovascular diseases. Nat Rev Nephrol. 2009; 5:203-211.

8. Cesari M, Pahor M, Incalzi RA. Plasminogen activator inhibitor-1 (PAI-1): a key factor linking fibrinolysis and age-related subclinical and clinical conditions. Cardiovasc Ther. 2010; 28:e72-91.

9. Verrijken A, Francque S, Mertens I, Prawitt J, Caron S, Hubens G, Van Marck E, Staels B, Michielsen P, Van Gaal L. Prothrombotic factors in histologically proven nonalcoholic fatty liver disease and nonalcoholic steatohepatitis. Hepatology. 2014; 59:121-129.

10. Alessi MC, Bastelica D, Mavri A, Morange P, Berthet B, Grino M, Juhan-Vague I. Plasma PAI-1 levels are more strongly related to liver steatosis than to adipose tissue accumulation. Arterioscler Thromb Vasc Biol. 2003; 23:1262-1268.

11. Shah C, Yang G, Lee I, Bielawski J, Hannun YA, Samad F. Protection from high fat diet-induced increase in ceramide in mice lacking plasminogen activator inhibitor 1. J Biol Chem. 2008; 283:13538-13548.

12. Ma LJ, Mao SL, Taylor KL, Kanjanabuch T, Guan YF, Zhang YH, Brown NJ, Swift LL, McGuinness OP, Wasserman DH, Vaughan DE, Fogo AB. Prevention of Obesity and Insulin Resistance in Mice Lacking Plasminogen Activator Inhibitor 1. Diabetes. 2004; 53:336-346.

13. Tamura Y, Kawao N, Yano M, Okada K, Matsuo O, Kaji H. Plasminogen activator inhibitor-1 deficiency ameliorates insulin resistance and hyperlipidemia but not bone loss in obese female mice. Endocrinology. 2014; 155:1708-1717.

14. Kanuri G, Spruss A, Wagnerberger S, Bischoff SC, Bergheim I. Fructose-induced steatosis in mice: role of plasminogen activator inhibitor-1, microsomal triglyceride transfer protein and NKT cells. Lab Invest. 2011; 91:885-895.

15. Hu PF, Chen H, Zhong W, Lin Y, Zhang X, Chen YX, Xie WF. Adenovirus-mediated transfer of siRNA against PAI-1 mRNA ameliorates hepatic fibrosis in rats. J Hepatol. 2009; 51:102-113.

16. Wang H, Zhang Y, Heuckeroth RO. PAI-1 deficiency reduces liver fibrosis after bile duct ligation in mice through activation of tPA. FEBS Lett. 2007; 581:3098-3104.

17. Bergheim I, Guo L, Davis MA, Duveau I, Arteel GE. Critical role of plasminogen activator inhibitor-1 in cholestatic liver injury and fibrosis. J Pharmacol Exp Ther. 2006; 316:592-600.

18. Izuhara Y, Yamaoka N, Kodama H, Dan T, Takizawa S, Hirayama N, Meguro K, van Ypersele de Strihou C, Miyata T. 
A novel inhibitor of plasminogen activator inhibitor-1 provides antithrombotic benefits devoid of bleeding effect in nonhuman primates. J Cereb Blood Flow Metab. 2010; 30:904-912.

19. Izuhara $Y$, Takahashi S, Nangaku M, Takizawa S, Ishida H, Kurokawa K, van Ypersele de Strihou C, Hirayama N, Miyata T. Inhibition of plasminogen activator inhibitor-1: its mechanism and effectiveness on coagulation and fibrosis. Arterioscler Thromb Vasc Biol. 2008; 28:672-677.

20. Boe AE, Eren M, Murphy SB, Kamide CE, Ichimura A, Terry D, McAnally D, Smith LH, Miyata T, Vaughan DE. Plasminogen activator inhibitor-1 antagonist TM5441 attenuates Nomega-nitro-L-arginine methyl ester-induced hypertension and vascular senescence. Circulation. 2013; 128:2318-2324.

21. Ichimura A, Matsumoto S, Suzuki S, Dan T, Yamaki S, Sato Y, Kiyomoto H, Ishii N, Okada K, Matsuo O, Hou FF, Vaughan DE, van Ypersele de Strihou C, et al. A small molecule inhibitor to plasminogen activator inhibitor 1 inhibits macrophage migration. Arterioscler Thromb Vasc Biol. 2013; 33:935-942.

22. Jeong BY, Uddin MJ, Park JH, Lee JH, Lee HB, Miyata T, Ha H. Novel Plasminogen Activator Inhibitor-1 Inhibitors Prevent Diabetic Kidney Injury in a Mouse Model. PLoS One. 2016; 11:e0157012.

23. Huang WT, Vayalil PK, Miyata T, Hagood J, Liu RM. Therapeutic value of small molecule inhibitor to plasminogen activator inhibitor-1 for lung fibrosis. Am J Respir Cell Mol Biol. 2012; 46:87-95.

24. GhoshAK, Rai R, Park KE, Eren M, Miyata T, Wilsbacher LD, Vaughan DE. A small molecule inhibitor of PAI-1 protects against doxorubicin-induced cellular senescence. Oncotarget. 2016; 7:72443-72457. https://doi.org/10.18632/ oncotarget.12494.

25. Eren M, Boe AE, Murphy SB, Place AT, Nagpal V, MoralesNebreda L, Urich D, Quaggin SE, Budinger GRS, Mutlu GM, Miyata T, Vaughan DE. PAI-1-regulated extracellular proteolysis governs senescence and survival in Klotho mice. PNAS. 2014; 111:7090-7095.

26. Piao L, Jung I, Huh JY, Miyata T, Ha H. A novel plasminogen activator inhibitor-1 inhibitor, TM5441, protects against high-fat diet-induced obesity and adipocyte injury in mice. Br J Pharmacol. 2016; 173:2622-2632.

27. Castello-Cros R, Bonuccelli G, Molchansky A, Capozza F, Witkiewicz AK, Birbe RC, Howell A, Pestell RG, Whitaker-Menezes D, Sotgia F, Lisanti MP. Matrix remodeling stimulates stromal autophagy, "fueling" cancer cell mitochondrial metabolism and metastasis. Cell Cycle. 2011; 10:2021-2034.

28. Canto C, Gerhart-Hines Z, Feige JN, Lagouge M, Noriega L, Milne JC, Elliott PJ, Puigserver P, Auwerx J. AMPK regulates energy expenditure by modulating NAD + metabolism and SIRT1 activity. Nature. 2009; 458:1056-1060.

29. Pessayre D. Role of mitochondria in non-alcoholic fatty liver disease. J Gastroenterol Hepatol. 2007; 22:S20-27.
30. Swiatkowska M, Szemraj J, Cierniewski CS. Induction of PAI-1 expression by tumor necrosis factor alpha in endothelial cells is mediated by its responsive element located in the 4G/5G site. FEBS J. 2005; 272:5821-5831.

31. Jung UJ, Choi MS. Obesity and its metabolic complications: the role of adipokines and the relationship between obesity, inflammation, insulin resistance, dyslipidemia and nonalcoholic fatty liver disease. Int J Mol Sci. 2014; 15:6184-6223.

32. Hebbard L, George J. Animal models of nonalcoholic fatty liver disease. Nat Rev Gastroenterol Hepatol. 2011; 8:35-44.

33. Than NN, Newsome PN. A concise review of non-alcoholic fatty liver disease. Atherosclerosis. 2015; 239:192-202.

34. Wu JW, Wang SP, Alvarez F, Casavant S, Gauthier N, Abed L, Soni KG, Yang G, Mitchell GA. Deficiency of liver adipose triglyceride lipase in mice causes progressive hepatic steatosis. Hepatology. 2011; 54:122-132.

35. Ong KT, Mashek MT, Bu SY, Greenberg AS, Mashek DG. Adipose triglyceride lipase is a major hepatic lipase that regulates triacylglycerol turnover and fatty acid signaling and partitioning. Hepatology. 2011; 53:116-126.

36. Lara-Castro C, Garvey WT. Intracellular lipid accumulation in liver and muscle and the insulin resistance syndrome. Endocrinol Metab Clin North Am. 2008; 37:841-856.

37. Saltiel AR. New Perspectives into the Molecular Pathogenesis and Treatment of Type 2 Diabetes. Cell. 2001; 104:517-529.

38. Lloyd CM, Phillips AR, Cooper GJ, Dunbar PR. Threecolour fluorescence immunohistochemistry reveals the diversity of cells staining for macrophage markers in murine spleen and liver. J Immunol Methods. 2008; 334:70-81.

39. Giannandrea M, Parks WC. Diverse functions of matrix metalloproteinases during fibrosis. Dis Model Mech. 2014; 7:193-203.

40. Pedroja BS, Kang LE, Imas AO, Carmeliet P, Bernstein AM. Plasminogen Activator Inhibitor-1 Regulates Integrin alpha $\mathrm{v}$ beta 3 Expression and Autocrine Transforming Growth Factor beta Signaling. J Biol Chem. 2009; 284:20708-20717.

41. Sunny NE, Bril F, Cusi K. Mitochondrial Adaptation in Nonalcoholic Fatty Liver Disease: Novel Mechanisms and Treatment Strategies. Trends Endocrinol Metab. 2016.

42. Perry RJ, Samuel VT, Petersen KF, Shulman GI. The role of hepatic lipids in hepatic insulin resistance and type 2 diabetes. Nature. 2014; 510:84-91.

43. Nassir F, Ibdah JA. Role of mitochondria in nonalcoholic fatty liver disease. Int J Mol Sci. 2014; 15:8713-8742.

44. Smith BK, Marcinko K, Desjardins EM, Lally JS, Ford RJ, Steinberg GR. Treatment of nonalcoholic fatty liver disease: role of AMPK. Am J Physiol Endocrinol Metab. 2016; 311:E730-E740.

45. Estall JL, Kahn M, Cooper MP, Fisher FM, Wu MK, Laznik D, Qu L, Cohen DE, Shulman GI, Spiegelman BM. Sensitivity of lipid metabolism and insulin signaling to genetic alterations in hepatic peroxisome proliferator- 
activated receptor-gamma coactivator-1 alpha expression. Diabetes. 2009; 58:1499-1508.

46. Morris EM, Meers GM, Booth FW, Fritsche KL, Hardin CD, Thyfault JP, Ibdah JA. PGC-1alpha overexpression results in increased hepatic fatty acid oxidation with reduced triacylglycerol accumulation and secretion. Am J Physiol Gastrointest Liver Physiol. 2012; 303:G979-992.

47. Scarpulla RC, Vega RB, Kelly DP. Transcriptional integration of mitochondrial biogenesis. Trends Endocrinol Metab. 2012; 23:459-466.
48. Lin J, Handschin C, Spiegelman BM. Metabolic control through the PGC-1 family of transcription coactivators. Cell Metab. 2005; 1:361-370.

49. Du X, Edelstein D, Rossetti L, Fantus IG, Goldberg H, Ziyadeh F, Wu J, Brownlee M. Hyperglycemia-induced mitochondrial superoxide overproduction activates the hexosamine pathway and induces plasminogen activator inhibitor-1 expression by increasing Sp1 glycosylation. Proc Natl Acad Sci USA. 2009; 97:12222-12226. 